\title{
Assessing biochar ecotoxicology for soil amendment by root phytotoxicity bioassays
}

Visioli, Giovanna; Conti, Federica D.; Menta, Cristina; Bandiera, Marianna; Malcevschi, Alessio; Jones, David; Vamerali, Teofilo

\section{Environmental Monitoring and Assessment}

DOI:

10.1007/s10661-016-5173-y

Published: 01/03/2016

Peer reviewed version

Cyswllt i'r cyhoeddiad / Link to publication

Dyfyniad o'r fersiwn a gyhoeddwyd / Citation for published version (APA):

Visioli, G., Conti, F. D., Menta, C., Bandiera, M., Malcevschi, A., Jones, D., \& Vamerali, T. (2016). Assessing biochar ecotoxicology for soil amendment by root phytotoxicity bioassays Environmental Monitoring and Assessment, 188(3). https://doi.org/10.1007/s10661-016-5173-y

\footnotetext{
Hawliau Cyffredinol / General rights

Copyright and moral rights for the publications made accessible in the public portal are retained by the authors and/or other copyright owners and it is a condition of accessing publications that users recognise and abide by the legal requirements associated with these rights.

- Users may download and print one copy of any publication from the public portal for the purpose of private study or research.

- You may not further distribute the material or use it for any profit-making activity or commercial gain

- You may freely distribute the URL identifying the publication in the public portal ?
}

Take down policy

If you believe that this document breaches copyright please contact us providing details, and we will remove access to the work immediately and investigate your claim. 
1 Ecotoxicological assessment of biochar quality by using phytotoxicity bioassays

3 Giovanna Visioli ${ }^{1 *}$, Federica D. Conti ${ }^{1}$, Cristina Menta ${ }^{1}$, Gerardo Palla $^{3}$, Marianna Bandiera ${ }^{2}$,

4 Alessio Malcevschi ${ }^{1}$, Teofilo Vamerali ${ }^{2}$

5

$6{ }^{1}$ Department of Life Sciences, University of Parma, Italy

$7 \quad{ }^{2}$ Department of Agronomy, Food, Natural Resources, Animals and the Environment, University of 8 Padova, Italy

$9{ }^{3}$ Department of Food Science, University of Parma, Italy

\section{$11{ }^{*}$ Corresponding author:}

12 Giovanna Visioli

13 Department of Life Sciences

14 University of Parma

15 Parco Area delle Scienze 11/A

1643124 Parma, Italy

17 Tel: +39-0521-905692

18 E-mail: giovanna.visioli@unipr.it

\section{Abstract}

21 Soil amendment with biochar has been proposed as effective in improving agricultural land fertility

22 and carbon sequestration, although the characterisation and certification of biochar quality are still

23 crucial for agronomic acceptance. Described here are the effects of four biochars (conifer and

24 poplar wood, grape marc, wheat straw) at increasing application rates $(0.5,1,2,5,10,20,50 \%$

$25 \mathrm{w} / \mathrm{w}$ ) on both germination and root elongation of Cucumis sativus L., Lepidium sativum L. and 
26 Sorghum saccharatum Moench. Biochars varied in chemical properties, depending on the type and

27 quality of the initial feedstock batch; PAHs were high in conifer and wheat straw, while $\mathrm{Cd}$ and $\mathrm{Cu}$

28 exceeded maximum permitted values for amendments in poplar and grape marc, respectively. With

29 our chars, electrical conductivity and $\mathrm{Cu}$ altered both germination and root elongation at $\geq 5 \%$ rate,

30 together with $\mathrm{Zn}$ at $\geq 10 \%$ and elevated $\mathrm{pH}$ at $\geq 20 \%$. Germination decreased only at very high rates

31 of grape marc and wheat straw chars, whereas root length was affected already at $0.5 \%$ of conifer

32 and poplar in cucumber and sorghum, with marked impairment in all chars at $>5 \%$. As a general

33 interpretation, it is proposed here a robust root phytotoxicity logarithmic model in sorghum, based

34 on biochar $\mathrm{Zn}$ content, which explains $66 \%$ of variability over the whole dosage range tested. We

35 conclude that metal contamination is a crucial quality parameter for biochar safety, and that root

36 elongation represents a stable test for assessing phytotoxicity at recommended amendment rates

$37(<1-2 \%)$.

38 Key-words: Biochar, Feedstock quality, Germination bioassay, Metal contamination, Root

39 phytotoxicity

\section{1. Introduction}

Biochar is a carbon-rich by-product resulting from waste plant material burned with little or

43 no oxygen at very high temperatures, usually between 300 and $1,000{ }^{\circ} \mathrm{C}$ (Jeffery et al., 2011;

44 Verheijen et al, 2010). In recent years, the importance of biochar for soil amendment has

45 substantially increased, mainly as a response to increased global carbon emissions and deterioration

46 of agricultural soil quality (Laird 2008; Lehmann, 2007). Due to its high porosity, specific surface

47 area and carbon content, biochar can decrease nutrient losses and water leaching, and enhance soil

48 cation exchange and water-retaining capacities (Chan et al., 2007; Lehman 2007). It can also adsorb

49 and immobilise persistent organic and inorganic pollutants (Beesley et al., 2010; Hale at al., 2011;

50 Oleszczuk et al., 2012; Fellet et al. 2014) and pesticides (Cao et al., 2011; Zheng et al., 2010) in 
51 sediments and soils, decreasing the potentially noxious effects associated with their

52 bioaccumulation through the food chain.

53 Despite these benefits, knowledge of soil-biochar interactions is still incomplete. Hazardous effects

54 may derive from phytotoxic compounds, particularly heavy metals and polycyclic aromatic

55 hydrocarbons (PAHs). Highly dangerous PAHs originate from degradation of lignin and cellulose

56 during production (Freddo et al., 2012; Kuśmierz and Oleszczuk, 2014; Oleszczuk et al., 2013) and

57 are adsorbed onto biochar surfaces (Sharma and Hajaligol, 2003). PAHs are of great environmental

58 concern, due to their toxic, mutagenic and carcinogenic properties, and their presence may

59 introduce unacceptable environmental, agronomic and human health risks when biochar is spread

60 for soil amendment (Kuśmierz and Oleszczuk, 2014). Working parameters during burning of

61 biomass (temperature, oxygen rate, supply feedstock rate, composition) can affect its chemical and

62 physical properties (Spokas, 2010). Hence, it is essential to develop rapid and reliable procedures

63 for biochar screening, to highlight the potentially negative effects on plant growth and human health

64 before large-scale applications.

65 Within this framework, we compared the effects of four biochars obtained from a standardised 66 gasification process and various feedstock batches, i.e., conifer and poplar wood, grape marc and 67 wheat straw, on the germination and root elongation of three plant species routinely used in 68 bioassay tests, i.e., Cucumis sativus L., Lepidium sativum L. and Sorghum saccharatum (L.)

69 Moench. We aimed at: i) assessing the quality of different feedstocks, ii) identifying the best 70 species as indicators of potential biochar toxicity, and iii) finding a relationship between biochar 71 characteristics and phytotoxicity.

\section{2. Materials and methods}




\subsection{Biochar production and characterisation}

Biochars were obtained by gasification in a fixed-bed, down-draft, open-core, compact gasifier (AGT Company, Italy) at $1,200{ }^{\circ} \mathrm{C}$ constant temperature. Four feedstock batches were used: mixed conifer wood (CO), poplar wood (PO), grape marc (GM) and wheat straw (WS). The effects of biochars were compared with a reference commercial green-waste composted amendment (CA) obtained after 6-8-month maturation. $\mathrm{pH}$ was measured with a glass electrode on $10 \mathrm{~g}$ of pulverised biochar diluted in $25 \mathrm{~mL}$ deionised water, after $1 \mathrm{~h}$ shaking and subsequent stabilisation. Concentrations of trace elements were revealed in $\sim 0.1-0.15 \mathrm{~g}$ DW homogenised samples after microwave-acid digestion (Milestone ETHOS 900, Bergamo, Italy). Samples were analysed by ICP-OES (SPECTRO CirOS Vision EOP, SPECTRO Analytical Instruments KG, Kleve, Germany). DTPA extraction was also performed following the Lindsay and Norwell protocol (1978). PAHs were quantified in 3-g samples treated with $50 \mathrm{~mL}$ of toluene (Sigma Aldrich, St. Louis, MO) for $3 \mathrm{~h}$ through Soxhlet equipment; the solvent was then evaporated and weighed. The residue was recovered with $1-2 \mathrm{~mL}$ toluene, adsorbed on a silica gel column and recovered by washing with $5 \mathrm{~mL}$ of toluene, concentrated to $0.1-0.5 \mathrm{~mL}$, spiked with $200 \mu \mathrm{g}$ of diphenyl (Sigma Aldrich) as internal standard, and injected ( $1 \mu \mathrm{L}$ split mode 1/20 ratio) in a GC-MS analyser (Agilent Technologies, Inc., Wilmington, DE) equipped with a 30-m capillary column (0.25-mm i.d., $0.25 \mathrm{mcm}$ f.t) connected with a 5-m silica pre-column (i.d. $0.53 \mathrm{~mm}$ ). MS data were recorded at 70 eV scan mode $(41-440 \mathrm{~m} / \mathrm{z})$

\subsection{Phytotoxicity bioassays}

Three plant species were used for biochar tests, i.e., Cucumis sativus L. (cucumber), Lepidium sativum L. (watercress) and Sorghum saccharatum (L.) Moench (sorghum). Seeds from each species were obtained from plants not previously treated with fungicides. Seed vitality was 
101 preliminarily assessed at $25 \pm 1{ }^{\circ} \mathrm{C}$ in deionised water, germination rates being generally $>90 \%$ for 102 all species. Seed germination and root elongation tests were performed according to OECD 103 regulations (1984). The four biochars and CA were pulverised and mixed with a standard soil (SS)

104 (70\% quartz sand, 20\% kaolinite, 10\% finely-ground Sphagnum peat, $\mathrm{pH} 8.0 \pm 0.2$ ) at 7 increasing 105 w/w rates: 0.5, 1, 2, 5, 10, 20 and 50\%, in comparison with SS alone, as untreated control. Tests 106 were performed directly on soil matrices because the elutriates could not always reflect the true 107 toxicity (Visioli et al., 2013; 2014). Four replicates per treatment were arranged by setting $15 \mathrm{~g}$ of 108 substrate in 9-cm diameter disposable Petri dishes, covered with Whatman \#1 filter paper and 109 wetted with $5 \mathrm{~mL}$ of deionised water. Ten undamaged plump seeds were placed on the filter and the 110 dishes were incubated at $25 \pm 2{ }^{\circ} \mathrm{C}$ in the dark for $72 \mathrm{~h}$. Germination rate was evaluated as number of 111 complete sprouts ( $\geq 1 \mathrm{~mm}$ long) of total number of seeds; shoot (sorghum only) and root lengths 112 were also measured with a digital gauge.

\subsection{Statistical analysis}

115

To ascertain differences between biochars, CA and SS, "many-to-one" multiple comparisons 117 were performed with Dunnett's test (Dunnett, 1955) as a follow-up to the one-way ANOVA 118 procedure. Both endpoints of the phytotoxicity tests (germination and root elongation) were

119 compared. When ANOVA revealed differences between CA and biochars, a multiple-comparison

120 Tukey's HSD test was carried out. A log-logistic model from the Ritz and Streibig 'drc' R package 121 (2005) was applied to fit the dose response of biochars and CA and to estimate the effective 122 concentrations $(\mathrm{Ec})$ responsible for reductions of 10,30 or $50 \%$ in root length. In $\mathrm{CO}$ and $\mathrm{PO}$ 123 biochars, the log-logistic model failed, and a linear interpolation was applied within the range 0$1240.5 \%$ (which accounted for almost all variability). A multiple linear regression (stepwise), 125 considering additive effects, was also used to verify the effects of different chemicals in biochars on 126 the reduction in root length. To facilitate interpretation of the large dataset regarding biochar quality 
and plant response, multivariate statistical analysis was applied at each tested biochar rate, to reduce

128 the number of variables by PCA (principal component analysis) and to identify common data

129 distribution patterns by cluster analysis. Before applying these, data were standardised by

130 subtracting the mean and dividing by standard deviation within each variable.

131 Factorial discriminant analysis (MDA, Multigroup Discriminant Analysis, with Wilks' lambda and

132 Pillai's trace tests) and PCA were applied to describe phytotoxicity and biochar quality based on

133 germination rate and root length, and chemical features of biochars (i.e., pH, EC, total PAHs and

134 metal rates: $\mathrm{Cd}, \mathrm{Co}, \mathrm{Cr}, \mathrm{Cu}, \mathrm{Hg}, \mathrm{Ni}, \mathrm{Pb}, \mathrm{Zn})$. Multivariate data normality was preliminarily verified

135 by the Shapiro test. Multivariate cluster analysis was used to describe the characteristics of

136 similarity among biochars and plant species. The data clustering algorithm was agglomerative

137 (bottom-up) with distance optimisation and similarity (Pearson's correlation coefficient) as

138 proximity method. The squared Euclidean distance and average link (UPGMA, Unweighted Pair

139 Group Method using Arithmetic Average) were used as cluster distance and linkage method,

140 respectively. In dendrograms, the maximum level of homogeneity within groups was calculated 141 with the method of Calinski and Harabasz (1974). All statistical analyses were performed with R 142 software (2013) and within MS Excel XLSTAT (Addinsoft, Paris, France).

\subsection{Chemical characteristics of biochars}

Chemical characterisation of the four biochars revealed some differences in $\mathrm{pH}$, metals and

149 PAH contents (Table 1a,b). All biochars were alkaline, $\mathrm{pH}$ varying from 8.6 in poplar to 10.4 in 150 grape marc. Only PO had a pH similar to that of SS and CA; the others were characterised by strong 151 alkalinity, with $\mathrm{pH}$ generally $>10$ (Table 1a). GM also showed the highest electrical conductivity $152\left(\mathrm{EC}>12 \mathrm{mS} \mathrm{cm}^{-1}\right), \sim 70 \times$ higher than that of $\mathrm{PO}$ and $\mathrm{CA}$. 
Metal concentrations were generally below the maximum admitted threshold recommended

154 by Italian legislation for amendments (Italian Legislative Decree 217/2006, in application of Reg.

155 CE n. 200313 October 2003). Metals above threshold were Cd in PO (+4\%) and, in particular, $\mathrm{Cu}$ 156 in GM (+60\%) (Table 1a).

157 Sixteen PAH species were revealed as the main pollutants, according to their potential mutagenic 158 properties (EPA, 2008). CO had the highest total PAH rate (>30 $\left.\mathrm{mg} \mathrm{kg}^{-1}\right)$, with considerably higher 159 concentrations of phenanthrene, anthracene and the carcinogenic benzo(b)fluoranthene compared 160 with the other feedstocks (Table 1 b). GM had the lowest value $\left(\sim 5 \mathrm{mg} \mathrm{kg}^{-1}\right)$, the order being $\mathrm{CO}>\mathrm{WS}>\mathrm{PO}>\mathrm{GM}$.

\subsection{Effects of biochars on seed germination and root elongation}

Seed germination of plant species was revealed at each tested biochar and CA rate (Fig. 1).

Cucumis sativus was not influenced at low rates, germination being significantly reduced with respect to controls $(\mathrm{P}<0.001)$ at only $>10 \%$ of $\mathrm{GM}$ and $>50 \%$ of WS. Lepidium sativum showed an increase in germination rate at all tested dilutions of $\mathrm{CO}$ and PO whereas, after initial enhancement, GM again became severely phytotoxic at $\geq 5 \%$ and WS at $\geq 50 \%$ (-40\% in germination). Similarly, in S. saccharatum $\mathrm{CO}$ and PO did not inhibit germination, but was seriously affected above $10 \%$ of GM and $50 \%$ of WS $(\mathrm{P}<0.001)$. GM was the most phytotoxic char, leading to complete inhibition of germination at $\geq 10 \%$ in watercress and $\geq 20 \%$ in cucumber and sorghum. CA did not negatively

173 influence germination at any rate.

Root growth was severely affected by biochar amendment (Fig. 2). Root length in C. sativus was significantly reduced at all biochar and tested rates $(\mathrm{P}<0.001)$. For this species, a marked fall in root elongation $(\sim 80 \%)$ was already observed at $0.5 \%$ of $\mathrm{CO}$ and $\mathrm{PO}$, followed by a stable response, whereas phytotoxicity increased progressively with amendment rate in GM and WS. CA also 
rate. Matching the complete inhibition of germination at $\geq 20 \%$ of $\mathrm{GM}$, root elongation was also impeded. L. sativum showed no inhibition in root length in $\mathrm{CO}$ and PO biochars, nor in CA, roots even being stimulated at all tested rates $(\mathrm{P}<0.001)$; conversely, GM and WS, after initial stimulation up to $1 \%$ and $2 \%$ of application, respectively, inhibited the root growth of this species; at $5 \%$ GM and $10 \%$ WS, root lengths drastically fell, with significant differences with respect to controls $(\mathrm{P}<0.001)$ (Fig. 2). Root and shoot lengths in S. saccharatum decreased gradually with increasing application rates of $\mathrm{CA}, \mathrm{GM}$ and $\mathrm{WS}(\mathrm{P}<0.001)$, whereas marked impairment was immediately observed at the lowest amendment rate $(0.5 \%)$ for $\mathrm{CO}$ and $\mathrm{PO}(\mathrm{P}<0.001)$ (Fig. 2).

Biochar application rates causing 10\%, 30\% and 50\% reductions in root length for each species were also estimated (Table SI1). Since estimates for PO and CO fell within the small application range of $0-0.5 \%$, in which the greatest variations occurred, they also provided the lowest values at the three effective concentrations, i.e., $~ 0.06-0.09 \%\left(\mathrm{Ec}_{10}\right), 0.12-0.18 \%\left(\mathrm{Ec}_{30}\right)$ and $0.30-0.44 \%$ $\left(\mathrm{Ec}_{50}\right)$, depending on species. Low Ec values were also found in GM in combination with sorghum. The $\mathrm{Ec}_{50}$ of GM was quite stable across species (1.6-3.7\%), but a larger variation was observed for WS (7.1-14.7\%). Matching the enhancement effect of all biochars within a $2 \%$ application rate (Fig. 2), L. sativum generally had a higher Ec compared with those of the other species (Table SI1).

ANOVA detected significant differences in root elongation between CA and biochars as average of application rates. Pairwise comparisons confirmed great reductions in length with $\mathrm{CO}$ in $C$. sativus and with GM in L. sativum; generalised growth impairment was observed in S. saccharatum (Table SI2).

Stepwise forward linear multiple regression applied to the whole dataset identified only electrical conductivity as a significant char parameter negatively related to root length, but the model explained only slight variability $\left(\mathrm{R}^{2}=0.15\right)$. When analysis was broken down by species, the $\mathrm{Zn}$ biochar rate appeared as the most important variable in both cucumber and sorghum, the coefficients of determination being 0.36 and 0.39 , respectively. A logarithm model in sorghum turned out to provide the most suitable and significant fit $\left(\mathrm{R}^{2}=0.66\right)$ to describe root length $(\mathrm{RL}, \%$ 
205 of unamended control) over $\mathrm{Zn}$ concentration $\left(\mathrm{mg} \mathrm{kg}^{-1}\right)$ corrected by biochar rate (BC\%), as 206 follows:

$\mathrm{RL}=64.162-11.81 * \ln (\mathrm{Zn} * \mathrm{BC} \%)$

\subsection{Principal component analysis and cluster analysis}

PCA based on chemical characteristics of biochars and standardised seed germination rate

212 and root length of plant species identified two dummy factors which explained $100 \%$ of variability.

213 The first factor (F1) accounted for almost all variability, i.e., $>89 \%$ in biochar classification and $214>77 \%$ in species classification, depending on amendment rate, so that only F1 is shown in Figs. 3 215 and 4.

216 At low amendment rates $(0.5-1 \%)$ of biochar classification, F1 was supported (loadings $>|0.5|)$ by 217 electrical conductivity (EC), $\mathrm{Ni}$ and $\mathrm{Cr}$, and seldom by $\mathrm{PAH}$ rate (Fig. 3). Although germination 218 parameters only became significant at $\geq 5 \%$ amendment, germination was initially negatively 219 correlated with EC and root length with $\mathrm{Ni}, \mathrm{Cr}$ and PAHs (Fig. 3). Germination was negatively 220 affected by $\mathrm{EC}$ and $\mathrm{Cu}$ at $\geq 5 \%$ amendment rate, together with $\mathrm{Zn}$ at $\geq 10 \%$ and elevated $\mathrm{pH}$ at $221 \geq 20 \%$, as highlighted by the opposite direction of their vectors compared with those of germination 222 rate and root length. In discriminant analysis, ellipsis overlaps and centroid positions generally 223 highlighted two different groups, GM with high EC and $\mathrm{Cu}+\mathrm{Zn}$ with maximum phytotoxicity, 224 distinguished from the other biochars or commercial amendment. Only at $50 \%$ rate could a third 225 group, represented by WS, be clearly plotted separately, with high $\mathrm{pH}$ and relatively high EC and 226 PAH, capable of markedly reducing germination and root length.

227 With regard to species classification, root length significantly supported Factor 1 at all amendment 228 rates, together with germination rate up to $2 \%$ of application. Both sorghum and cucumber were 229 classified together as more sensitive species than watercress in highlighting phytotoxicity, with 230 substantial indifference in species choice at 50\% biochar rate only (Fig. 4). 
231 At all amendment rates, the hierarchical ascendant classification of biochar-species interaction was

232 a good descriptor of biochar type, regardless of choice of species (Fig. 5). According to the 233 maximum level of similarity, the first group included poplar as the safest biochar source, with low

$234 \mathrm{EC}, \mathrm{pH}$ and $\mathrm{Cu}$ contamination, together with the commercial amendment; the second group 235 included conifer and wheat straw. Grape marc was classified by itself in the third group, with 236 critical salinity, $\mathrm{pH}$ and metal contamination.

\section{Discussion}

\subsection{Feedstock and biochar quality}

Biochar quality largely depends on the chemical and physical characteristics of the initial batch waste and gasification/pyrolysis parameters. Feedstock quality includes the rate of ash, together with plant nutrients and heavy metals, lignin, cellulose and hemicellulose rates, all having a substantial effect on chemical reactions during the semi-anoxic conditions of combustion and thus potentially leading to accumulation of undesirable and directly toxic compounds. This implies large variability in biochar composition and its impact on soil and plants, making difficult its certification.

Metal rates, together with $\mathrm{EC}$ and $\mathrm{pH}$, are essential chemical characteristics for establishing biochar safety (Mukherjee and Lal, 2014; Lehmann and Joseph, 2009). In our experiment, biochar pH was rather variable but generally high, although we did establish its negative influence on plants at very

253 high application rates (>50\%) and in the literature the alkalinisation effect in the open is reported to 254 be short-lasting (Lucchini et al., 2014). However, alkalinity is also related to high EC, which may 255 be unsuitable for seed germination and initial root growth within wider ranges of application (5$25650 \%$ ). The characteristics of GM char, which was very rich in $\mathrm{Cu}$ as a result of common treatments 
against fungal diseases in vineyards under both organic and conventional types of management, revealed the full effects of this metal. The illegal $\mathrm{Cu}$ rate is expected to have a direct phytotoxic effect on seedlings and to contribute to raising $\mathrm{pH}$ and $\mathrm{EC}$. The good affinity of $\mathrm{Cu}$ to organic matter may mitigate its toxicity, but this probably did not occur in the crystalline structure of

261 biochar, and the high Zn level also contributed towards GM phytotoxicity.

262 It is true that metal mobility is effectively reduced by high $\mathrm{pH}$ through stimulation of metal 263 adsorption and precipitation (Beesley et al., 2011; Zhang et al., 2013), and we found moderate 264 DTPA-extractable fractions of all metals in biochars, maximum bioavailability being for Cd in WS 265 ( $18 \%$ of total), followed by $\mathrm{Cu}$ in $\mathrm{CO}(\sim 10 \%)$ and $\mathrm{Zn}$ in PO ( 6\%) (Table 1a). The considerable effects of heavy metals in germination occur at high biochar rates, and soluble metal fractions play a more important role in seedling growth than in completion of germination. Germination is certainly a delicate phase, but root elongation is more sensitive to adverse external conditions, a result already found in the case of high levels of soluble toxic metals in hydroponics (Vamerali et al., 2014).

Chemical characterisation of the four biochars revealed differences in PAH concentrations, conifer CO showing the highest rate (Table 1b). In soils, PAHs degrade slowly, and the high sorption capacity of biochars can extend their degree of environmental hazard over time (Kuśmierz and Oleszczuk, 2014; Quilliam et al., 2013), although our PCA results never indicated any important role of PAHs in seed germination and initial root elongation. Total PAHs includes several toxic compounds with generally low water solubility, and even the more soluble naphthalene and fluorene were very low or below detection limits. Root PAH concentrations are hardly altered by 278 various types of biochars (Brennan et al., 2014), and in our case the absence of any direct root/substrate contact also excludes the possibility of demonstrating the influence of this compound 280 class on seedling growth. The negative influence of wood-derived chars observed on root 281 elongation is probably due to high $\mathrm{Ni}+\mathrm{Cr}+\mathrm{Zn}$ and $\mathrm{Cd}$ in $\mathrm{CO}$ and $\mathrm{PO}$, respectively, some also 282 exceeding maximum permissible levels for amendments. In markedly metal-contaminated 
environments, biochar can also enhance root growth through metal immobilisation, indicating that metal bioavailability is one of the main limiting factors in plant growth (Brennan et al., 2014).

\subsection{Species choice as indicator of biochar toxicity}

The main problem in biochar management of agricultural land is to identify and standardise the chemical and physical indicators of quality (Lehmann and Joseph, 2009), in order to relate these characteristics to the potential ecological and toxicological effects on soil-living organisms and crop productivity (Lehmann et al., 2011).

Germination and root elongation are the most common tests in soil bioassays for checking compound toxicity (Calvelo Pereira et al., 2010; Chigbo and Batty, 2013; Lin and Xing, 2007). Several authors report that these tests are also effective in assessing biochar contamination (Rogovska et al., 2012; Solaiman et al., 2012). As plant species may substantially differ in their sensitivity to contaminants, our results show that seed germination was not greatly affected in all species, whereas root elongation suffered to an extent which depended on choice of species (Figs. 1, 2). Although germination was reduced only at high biochar rate (e.g., 5-10\% for GM), an earlier response may be expected when metal contamination increases greatly, as in biochars derived from wood treated with $\mathrm{Cu}$-based preservatives, the $\mathrm{Cu}$ rate of which may be up to 60 times higher than the rate we found (Lucchini et al., 2014). Instead, root length is considerably affected already at low rates, as cell division/elongation in root tips is very sensitive to soil contaminants (Halušková et al., 2010).

Feedstock quality plays an important role in biochar composition and phytotoxicity, but the contrasting response among plant species to the same biochar was unexpected, e.g., the root length of C. sativus and S. saccharatum was suddenly reduced by wood-based PO and CO biochars. Their low effective concentration values $\left(\mathrm{Ec}_{\mathrm{x}}\right)$ match recent finding on root elongation inhibition by 
wood-based biochars (Jeffery et al., 2011). The behaviour of L. sativum, which shows root

310 stimulation under wood-based biochars and CA, the latter also deriving from wood residues, and

311 under low rates of GM and WS, is probably due to its higher tolerance to metal contamination. The

312 Brassicaceae include several hyperaccumulator species, and cellular metal chelation is an accepted

313 defence strategy (Anjum et al., 2012). This response suggests that bioassays should focus on the

314 more stable behaviour of sorghum roots across the biochar types and CA, as evidenced by our $\mathrm{Zn}$

315 rate-based logarithm model. In C. sativus, Zn contamination was also the most suitable variable of 316 this model $\left(\mathrm{R}^{2}=0.47\right)$, followed by $\mathrm{pH}\left(\mathrm{R}^{2}=0.47\right)$, whereas the initial lag interval (up to $2-5 \%$

317 biochar rate) and the contrasting effects of chars in L. sativum caused the model to fail. For this 318 species, electrical conductivity was the most constraining factor.

319 C. sativus is a sensitive and therefore key plant in phytotoxicity bioassays (Wang et al. 2001), 320 although $S$. saccharatum seems a more informative species for biochar investigations. We were 321 surprised to find that L.sativum was less sensitive, but this may partly depend on the relatively good quality of our chars and on the type of vegetal matrix, which affects contaminant mobility.

\section{Conclusions}

At present, there are no clear indicators for the agronomic acceptance of biochar, mainly due to uncertainty regarding its quality and difficulties in predicting interactions with plants and soil biota. Watercress, cucumber and sorghum can all reveal phytotoxicity by reducing their germination rate, albeit only at very high biochar rates. Higher sensitivity, compatible with recommended amendment rates (1-2\%), can be easily retrieved from root elongation data. We demonstrate that metal contamination is the most critical constraint for plant growth, and increased metal loads in

332 agricultural land can also exacerbate metal leaching and subsequent groundwater and food chain 333 contamination. Although results on young seedlings must be confirmed in adult plants, these 334 bioassays provide rapid information for char screening. Again, the lack of real long-term studies on 
335 biochar effects in cultivated land, identifying contamination in the feedstock stream before 336 gasification/pyrolysis remains a crucial step before large-scale applications of biochar become 337 feasible.

\section{References}

Anjum NA, Ahmad I, Pereira ME, Duarte AC, Umar S, Khan NA. The Plant Family Brassicaceae: Contribution Towards Phytoremediation. Springer: Dordrecht, Heidelberg, New York, London, 2012.

Beesley L, Moreno-Jiménez E, Gomez-Eyles JL. Effects of biochar and greenwaste compost amendments on mobility, bioavailability and toxicity of inorganic and organic contaminants in a multi-element polluted soil. Environ Pollut 2010;158: 2282-2287.

Beesley L, Moreno-Jiménez E, Gomez-Eyles JL, Harris E, Robinson B, Sizmur T. A review of biochars' potential role in the remediation, revegetation and restoration of contaminated soils. Environ. Pollut. 2011;159: 3269-3282.

Brennan A, Moreno-Jiménez E, Puschenreiter M, Alburquerque JA, Switzer C. Effects of biochar amendment on root traits and contaminant availability of maize plants in a copper and arsenic impacted soil. Plant Soil 2014;379:351-360.

Brennan A, Moreno-Jiménez E, Alburquerque JA, Knapp CW, Switzer C. Effects of biochar and activated carbon amendment on maize growth and the uptake and measured availability of polycyclic aromatic hydrocarbons (PAHs) and potentially toxic elements (PTEs). Environ.

358 Calinski RB, Harabasz J. A dendrite method for cluster analysis. Communications in Stat 1974;3: $1-27$.

360 Calvelo Pereira R, Monterroso C, Macías F. Phytotoxicity of hexachlorocyclohexane: effect on germination and early growth of different plant species. Chemosphere 2010; 79: 326-333. 
362 Cao X, Ma L, Liang Y, Gao B, Harris W. Simultaneous immobilization of lead and atrazine in contaminated soils using dairy-manure biochar. Environ Sci Technol 2011;45: 4884-4889.

364 Chan K, Van Zwieten L, Meszaros I, Downie A, Joseph S. Agronomic values of greenwaste biochar as soil amendment. Soil Res 2007;45: 629-634.

Chigbo C, Batty L. Effect of combined pollution of chromium and benzo(a)pyrene on seed growth of Lolium perenne. Chemosphere 2013; 90:164-169.

Dunnet, CW. A multiple comparison procedure for comparing several treatments with a control. J. Amer Stat Assoc 1955;50:1096-1121.

EPA (United States Environmental Protection Agency). Polycyclic Aromatic Hydrocarbons (PAHs). Office of Solid Waste, Washington DC 20460, 2008.

372 Fellet G, Marmiroli M, Marchiol L. Elements uptake by metal accumulator species grown on mine tailings amended with three types of biochar. Sci Total Environ 2014;468-469, 598-608

374 Freddo A, Cai C, Reid BJ. Environmental contextualisation of potential toxic elements and polycyclic aromatic hydrocarbons in biochar. Environ Pollut 2012;171:18-24.

Hale SE, Hanley K, Lehmann J, Zimmerman A, Cornelissen G. Effects of chemical, biological, and physical aging as well as soil addition on the sorption of pyrene to activated carbon and biochar. Environ Sci Technol 2011;45:10445-10453.7

Halušková L, Valentovičová K, Huttová J, Mistrík I, Tamás L. Effect of heavy metals on root growth and peroxidase activity in barley root tips. Acta Physiol Plant 2010;32: 59-65.

Jeffery S, Verheijen FGA, van der Velde M, Bastos AC. A quantitative review of the effects of biochar application to soils on crop productivity using meta-analysis. Agr Ecosyst Environ 2011, 144:175-187.

Kuśmierz M, Oleszczuk P. Biochar production increases the polycyclic aromatic hydrocarbon content in surrounding soils and potential cancer risk. Environ. Sci. Pollut. Res 2014; 21: 3646-3652. 
Laird DA. The charcoal vision: A win-win scenario for simultaneously producing bioenergy, permanently sequestering carbon, while improving soil and water quality. Agron J 2008; 100: $178-181$.

Lehmann J. A handful of carbon. Nature 2007; 447: 143-144.

391 Lehmann J, Joseph S. Biochar for Environmental Management: Science and Technologies. Earthscan, London, UK, 2009.

393 Lehmann J, Rilling MC, Thies J, Masiello CA, Hockaday WC, Crowley D. Biochar effects on soil biota - a review. Soil Biol Biochem 2011;43:1812-1836.

Lin D, Xing B. Phytotoxicity of nanoparticles: inhibition of seed germination and root growth. Environ. Poll. 2007;150:243-250.

Lindsay, WL, Norwel WA. Development of a DTPA soil test for zinc, iron, manganese, and copper. Soil Sci Soc Am J 1978;42: 421-428.

Lucchini P, Quilliam RS, DeLuca TH, Vamerali T, Jones DL. Increased bioavailability of metals in two contrasting agricultural soils treated with waste wood-derived biochar and ash. Environ Sci Pollut Res 2014;21:3230-3240.

Maila MP, Cloete TE. Germination of Lepidium sativum as a method to evaluate polycyclic aromatic hydrocarbons (PAHs) removal from contaminated soils. Int Bioter Biodeg 2002;50:107-113.

OECD, 1984. Terrestrial Plants: Growth Test. OECD Guidelines for Testing of Chemicals, Paris: $\mathrm{N}^{\circ} 208$.

Oleszczuk P, Jośko I, Kuśmierz. Biochar properties regarding contaminant content and ecotoxicological assessment. J Hazard Mater 2013;260: 375-382.

Oleszczuk P, Rycaj M, Lehmann J, Cornelissen G. Influence of activated carbon and biochar on 
413 Quilliam RS, Rangecroft S, Emmett BA, Deluca TH, Jones DL. Is biochar a source or sink for polycyclic aromatic hydrocarbon (PAH) compounds in agricultural soils? GCB Bioenergy 2013; 5:96-103.

R Core Team. R: A Language and Environment of Statistical Computing. R Foundation for Statistical Computing, Vienna, Austria, 2013.

Ritz C, Streibig J C.Bioassay analysis using R. J. Statist. Software, Vol 12, Issue 5, 2005.

419 Rogovska N, Laird D, Cruse RM, Trabue S, Heaton E. Germination tests for assessing biochar quality. J Environ Qual 2012; 41: 1-9.

Sharma RK, Hajaligol M R. Effect of pyrolysis conditions on the formation of polycyclic aromatic hydrocarbons (PAHs) from polyphenolic compounds. J. Anal. Appl. Pyrolysis 2003;66: 123-144.

Solaiman ZM, Murphy DV, Abbott LK. Biochars influence seed germination and early growth of seedlings. Plant Soil 2012;353: 273-287

Spokas KA.Review of the stability of biochar in soils: predictability of O:C molar ratios. Carbon Mang 2010;1(2):289-303.

Sun L, Liao X, Yan X, Zhu G, Ma D. Evaluation of heavy metal and polycyclic aromatic hydrocarbons accumulation in plants from typical industrial sites: potential candidate in phytoremediation for co-contamination. Environ Sci Pollut Res 2014; 21: 12494-12504.

Vamerali T, Bandiera M, Lucchini P, Dickinson NM, Mosca G. Long-term phytomanagement of metal-contaminated land with field crops: integrated remediation and biofortification. Eur $\mathbf{J}$ Agron 2014;53:56-66. plant species for testing Ni contamination in soil. Bull. Environ. Contam. Toxicol. 2014;92: 490-496. 
439 Visioli G, Menta C, Gardi C, Conti FD. Metal toxicity and biodiversity in serpentine soils: $440 \quad$ application of bioassay tests and microarthropod index. Chemosphere 2013;90:1267-1273.

441 Wang X, Sun C, Gao S, Wang L, Shuokui H. Validation of germination rate and root elongation as 442 indicator to assess phytotoxicity in Cucumis sativus. Chemosphere 2001;44:1711-1721.

443 Zhan XH, Ma HL, Zhou IX, Liang JR, Liang TH, Xu GH Accumulation of phenanthrene by roots 444 of intact wheat (Triticum aestivum L.) seedlings: passive or active uptake? BMC Plant Biol $445 \quad 2010 ; 10: 52-60$.

446 Zhang X, Wang H, He L, Lu K, Sarmah A, Li J, Bolan NS, Pei J, Huang H. Using biochar for 447 remediation of soils contaminated with heavy metals and organic pollutants. Environ Sci Pollut Res 2013;20: 8472-8483.

449 Zheng W, Guo M, Ghow T, Bennet DN, Rajagopalan N. Sorption properties of greenwaste biochar 450 for two triazine pesticides. J. Hazard Mater. 2010;181:121-126. 
C. sativus

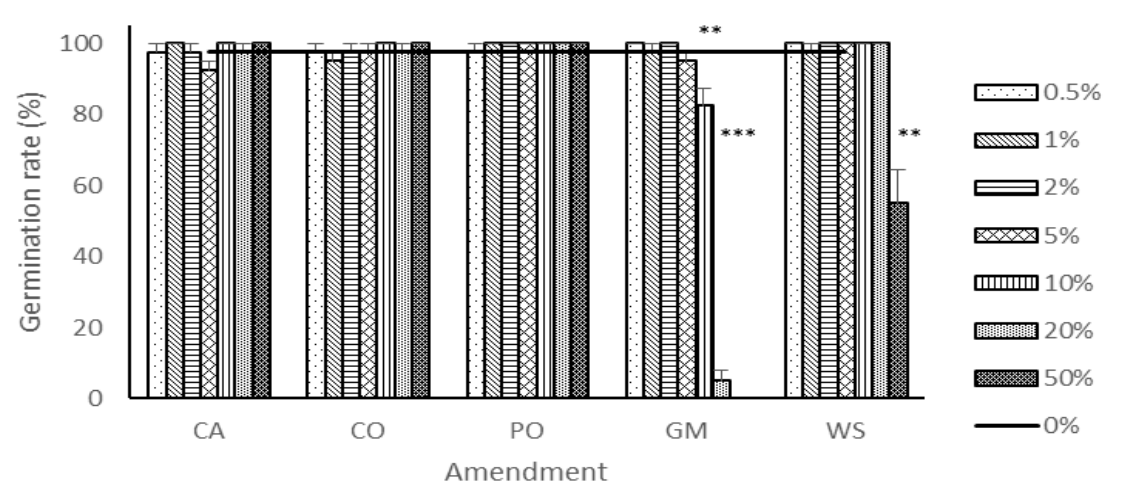

453

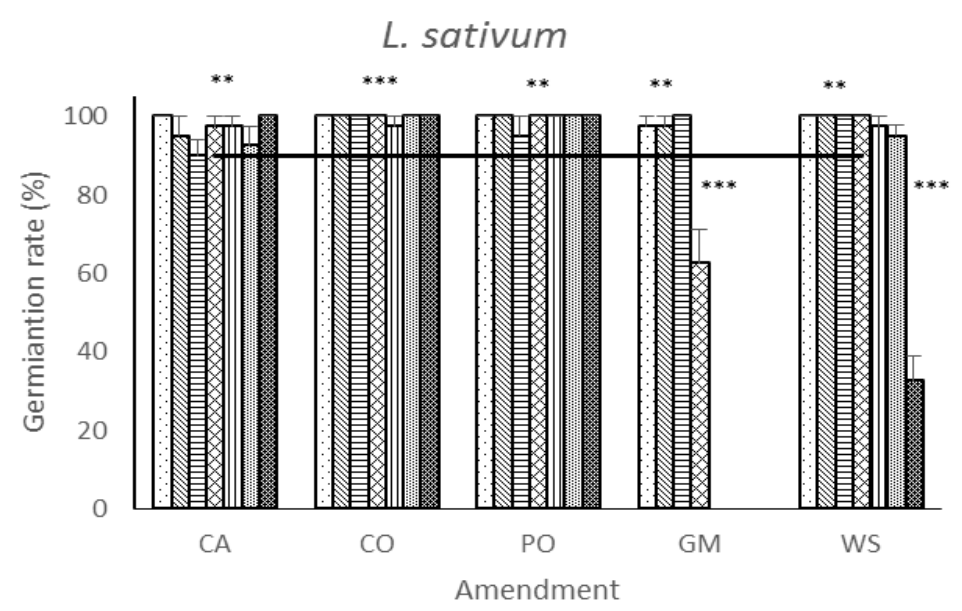

454

\section{S. saccharatum}

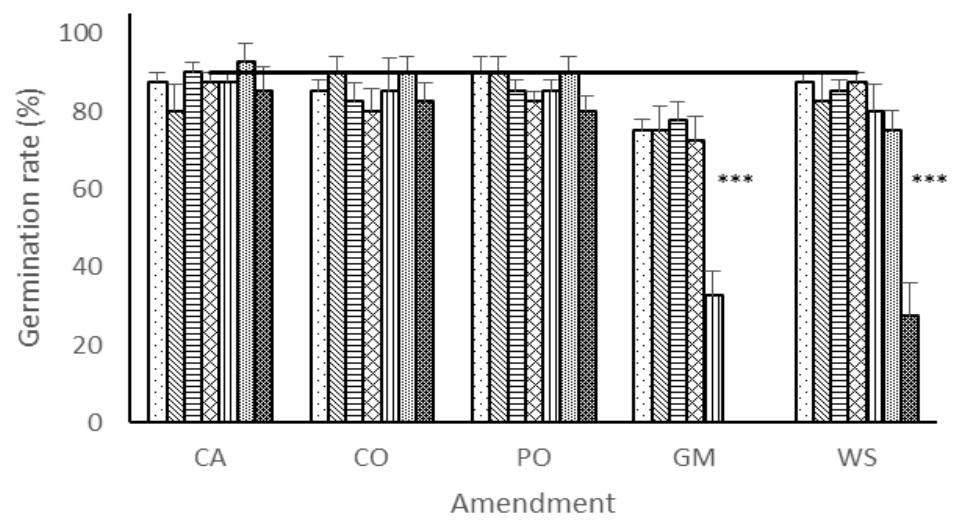

456 Figure 1: Percentage germination (mean value $\pm \mathrm{SE}, \mathrm{n}=4$ ) of tested species at different biochar 457 rates, compared with commercial amendment (CA) and unamended control (horizontal bar). 458 Asterisks: significant differences between amendments and control $(* *=\mathrm{P}<0.01 ; * * *=\mathrm{P}<0.001)$. 


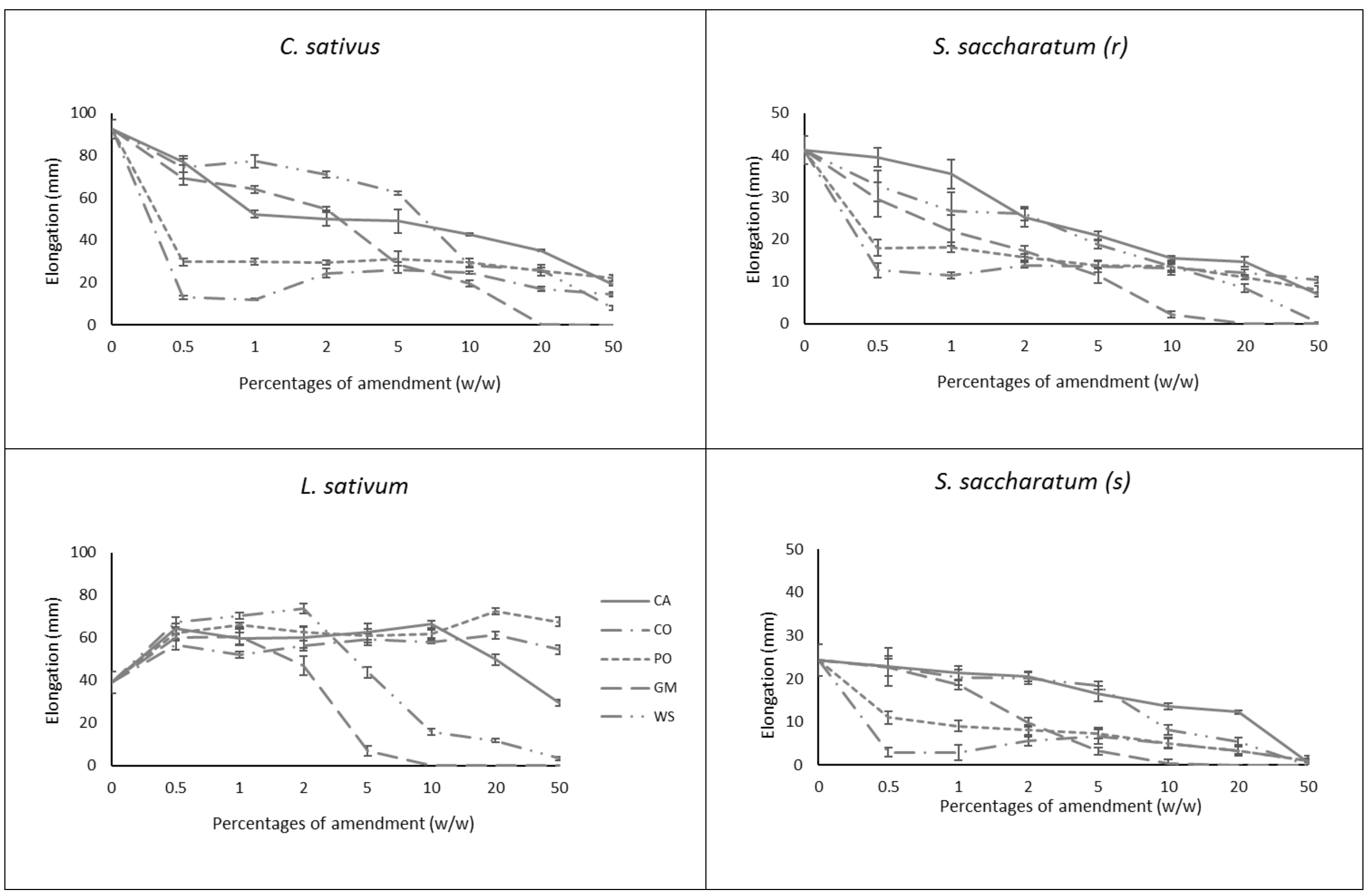


459 Figure 2: Shoot (s) (only sorghum) and root $(r)$ lengths (mean value \pm SE, $n=4$ ) after germination experiment in three species under increasing 460 biochar rates, compared with commercial amendment (CA). Note different scale among graphs. 

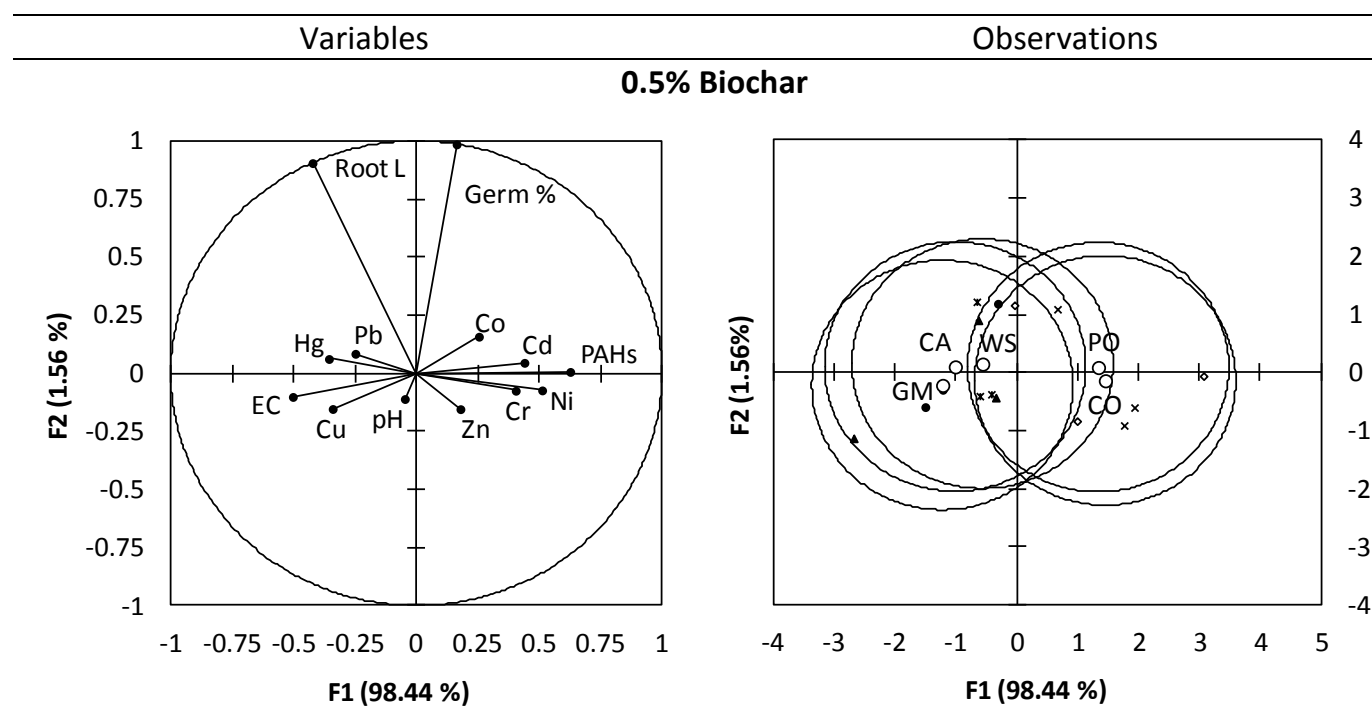

$\mathrm{pH}$

$-0.50$

EC

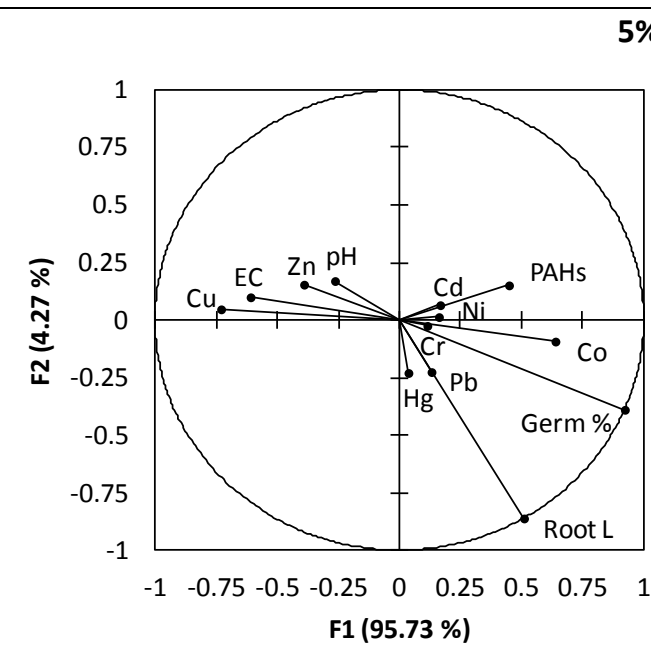

\section{5\% Biochar}

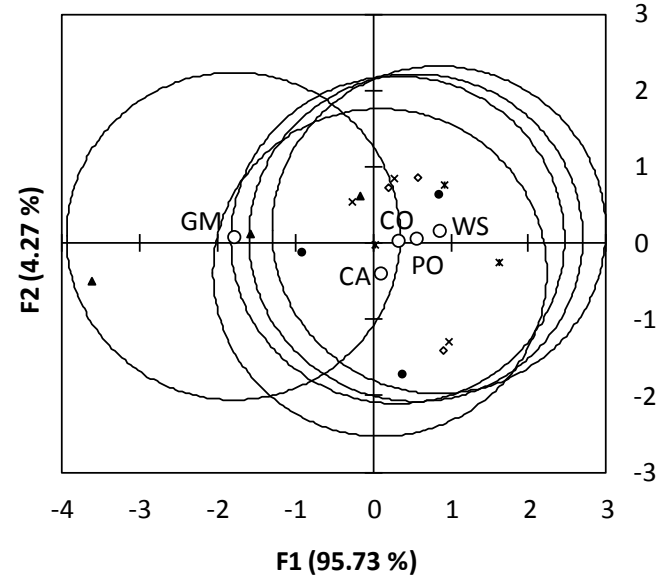

$\mathrm{pH}$

$-0.61$

EC

$\mathrm{Cd}$

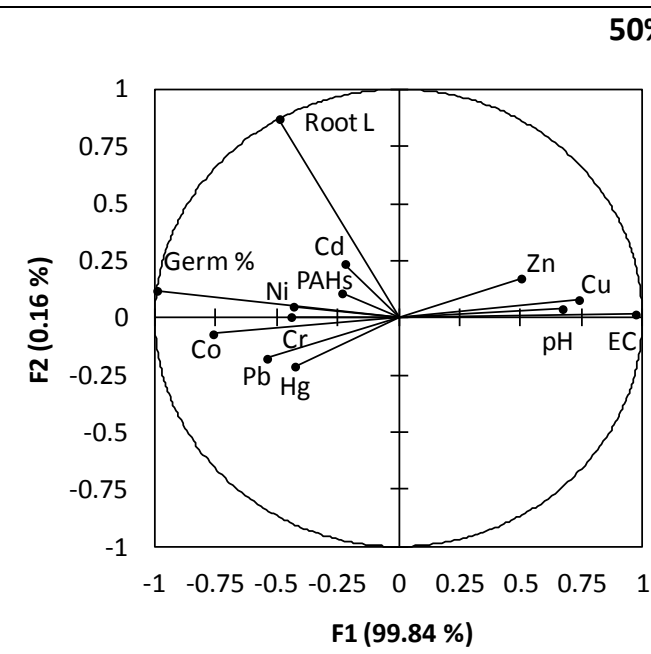

0\% Biochar

0.67

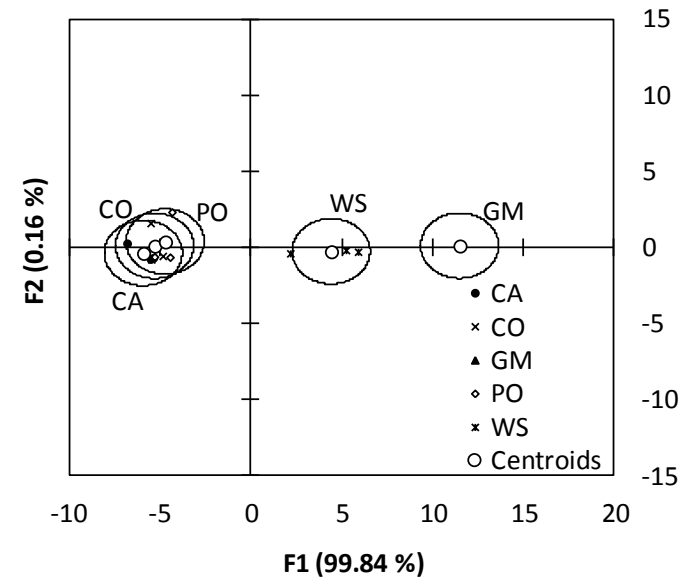

$\mathrm{pH}$

0.97

EC

$\mathrm{Cd}$

Co

$-0.44$

$\mathrm{Cr}$

0.74

$\mathrm{Cu}$

$\mathrm{Hg}$

$-0.43$

$\mathrm{Ni}$

$-0.43$

$\mathrm{Pb}$

$-0.54$

$\mathrm{Zn}$

0.50

PAHs

$-0.23$

Germ \%

$-0.99$

Root L

$-0.50$

Figure 3: PCA with F1 loadings (highlighted values $>|0.5|$ ) and DA for biochar classification at 3 462 selected amendment rates, considering chemical characteristics of biochars, germination rate (Germ $463 \%$ ) and root length (Root L). 


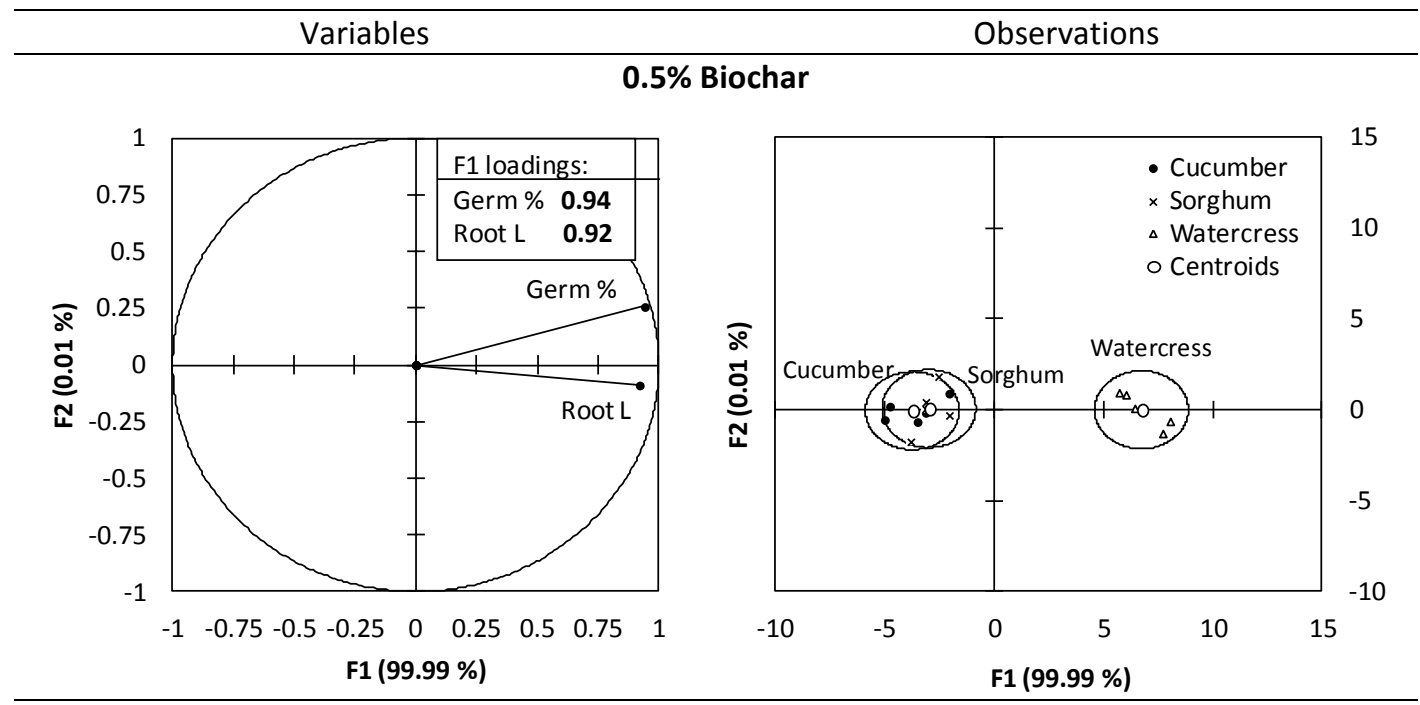

5\% Biochar
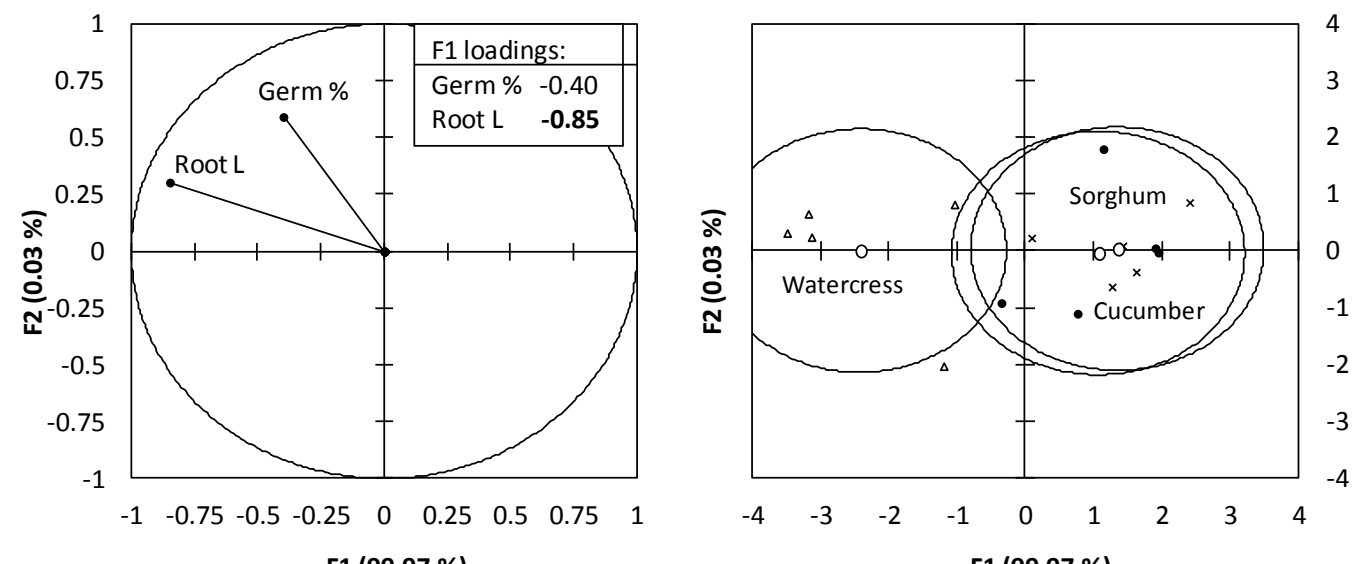

F1 (99.97\%)

$50 \%$ Biochar
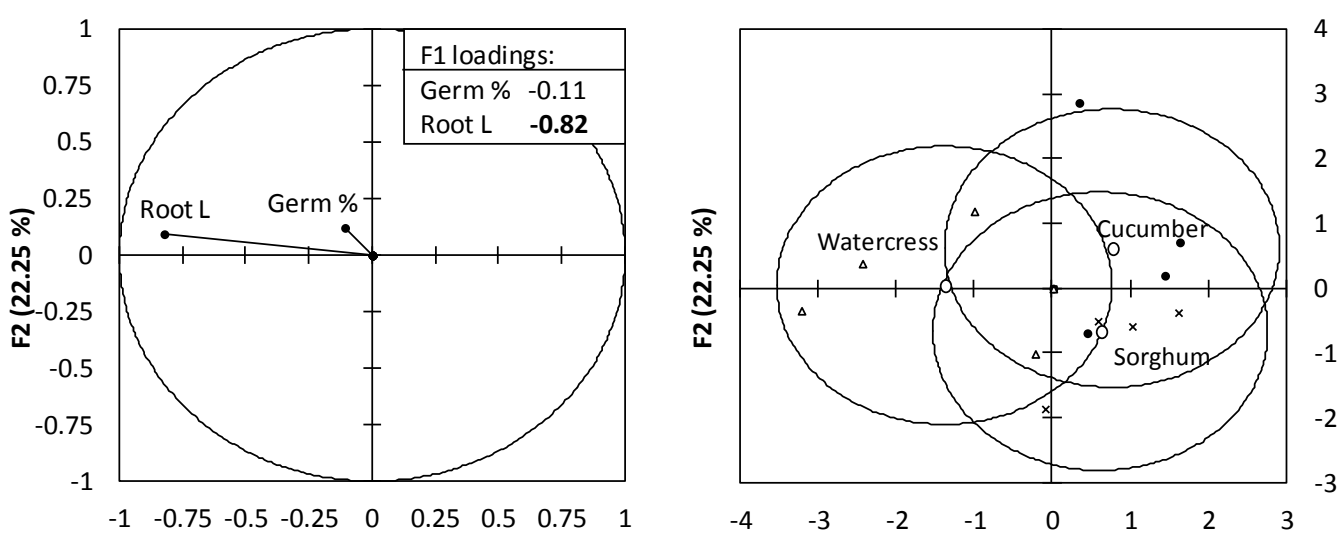

F1 (77.75\%)

F1 (77.75\%)

466 Figure 4: PCA and F1 loadings (highlighted values $>|0.5|)$ for species classification at 3 selected 467 amendment rates, considering germination rate (Germ \%) and root length (Root L). Loadings of 468 chemical characteristics of biochars: always nil. 


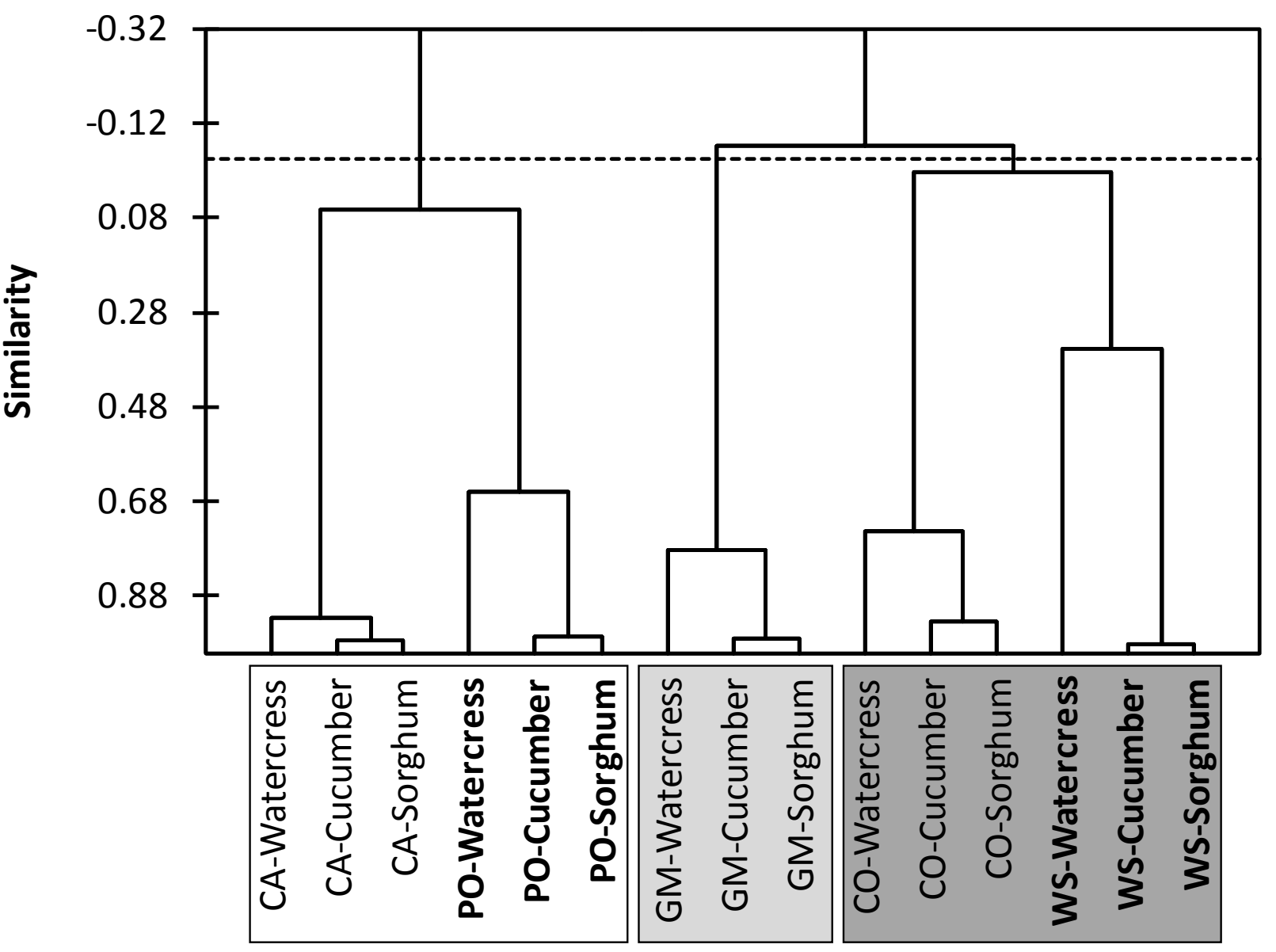

471 Figure 5: Cluster analysis of biochar/species combinations at $0.5 \%$ amendment rate, based on 472 chemical characteristics of biochars and germination rate and root length of 3 species. Horizontal 473 dashed line: maximum level of homogeneity within groups. Similar classification obtained at all 474 amendment rates. 
476 Table 1a: Main chemical proprieties of biochars in comparison with standard soil (SS) and 477 commercial amendment (CA)

478

\begin{tabular}{cccccccc}
\hline & IGV & SS & CA & CO & PO & GM & WS \\
\hline $\mathrm{pH}$ & - & 8.0 & 8.2 & 10.2 & 8.6 & 10.4 & 10.1 \\
$\mathrm{EC}\left(\mathrm{mS} \mathrm{cm}^{-1}\right)$ & - & $\mathrm{ND}$ & 0.15 & 0.62 & 0.17 & 12.2 & 4.79 \\
$\mathrm{Cd}\left(\mathrm{mg} \mathrm{kg}^{-1} \mathrm{DW}\right)$ & 1.50 & $<0.001$ & 0.29 & $0.34(12.7)$ & $\mathbf{1 . 5 6}(14.3)$ & $0.47(8)$ & $0.41(17.8)$ \\
$\mathrm{Co}\left(\mathrm{mg} \mathrm{kg}^{-1} \mathrm{DW}\right)$ & - & 6.13 & 2.71 & $2.05(<3.1)$ & $2.74(<3.1)$ & $1.29(<3.1)$ & $2.43(<3.1)$ \\
$\mathrm{Cr}$ total $\left(\mathrm{mg} \mathrm{kg}^{-1} \mathrm{DW}\right)$ & - & 89.2 & 47.1 & $114(1)$ & $23.5(<0.2)$ & $30.3(<0.2)$ & $29.5(<0.2)$ \\
$\mathrm{Cu}\left(\mathrm{mg} \mathrm{kg}^{-1} \mathrm{DW}\right)$ & 230 & 3.56 & 53.8 & $111(10.1)$ & $34.9(3.3)$ & $\mathbf{3 6 9}(1.8)$ & $26.5(5.5)$ \\
$\mathrm{Hg}\left(\mathrm{mg} \mathrm{kg}^{-1} \mathrm{DW}\right)$ & 1.50 & $<0.002$ & $<0.002$ & $<0.001(-)$ & $<0.001(-)$ & $<0.001(-)$ & $<0.001(-)$ \\
$\mathrm{Ni}\left(\mathrm{mg} \mathrm{kg}^{-1} \mathrm{DW}\right)$ & 100 & 53.0 & 22.0 & $85.4(0.7)$ & $18.9(1.6)$ & $16.2(0.7)$ & $19.4(1.8)$ \\
$\mathrm{Pb}\left(\mathrm{mg} \mathrm{kg}^{-1} \mathrm{DW}\right)$ & 140 & 7.32 & 27.7 & $6.34(3.6)$ & $10.7(4.8)$ & $5.23(<2)$ & $6.92(2)$ \\
$\mathrm{Zn}\left(\mathrm{mg} \mathrm{kg}^{-1} \mathrm{DW}\right)$ & 500 & 25.0 & 106 & $272(4.7)$ & $180(6.2)$ & $282(2.2)$ & $183(4.1)$ \\
\hline
\end{tabular}

Highlighted values exceed Italian Guidelines Values (IGV) for total metal rate in amendments. In 481 brackets: \% of metal bioavailability (DTPA-extraction). The analysis was performed in duplicate. $482 \mathrm{ND}=$ not detected 
484 Table 1b: Polycyclic aromatic hydrocarbons (PAHs) rates $\left(\mathrm{mg} \mathrm{kg}^{-1}\right)$ in biochars.

485

\begin{tabular}{lcccc}
\hline \multicolumn{1}{c}{ PAHs } & CO & PO & GM & WS \\
\hline Naphtalene & ND & 0.1 & 0.19 & ND \\
Acenaphthylene & 0.27 & 0.15 & 2.29 & ND \\
Acenaphthene & 0.05 & ND & ND & ND \\
Fluorene & ND & ND & ND & 0.19 \\
Phenanthrene & 5.29 & 2.08 & ND & 1.41 \\
Anthracene & 0.93 & 0.44 & ND & 0.23 \\
Fluoranthene & 3.12 & 1.28 & 0.13 & 4.91 \\
Pyrene & 3.80 & 2.14 & 0.37 & 4.95 \\
Benz(a)anthracene & 1.40 & 1.50 & 0.07 & 1.22 \\
Chrysene & 1.33 & 0.87 & 0.09 & 1.14 \\
Benzo(b)fluoranthene & 2.16 & 1.74 & 0.06 & 0.97 \\
Benzo(k)fluoranthene & 0.00 & 1.41 & 0.10 & ND \\
Benzo(a)pyrene & 1.20 & 1.62 & 0.10 & 0.45 \\
Dibenz(a,h)anthracene & ND & ND & ND & ND \\
Benzo(ghi)perylene & 0.88 & 1.72 & 0.14 & 0.27 \\
Indeno(1,2,3-C,D)pyrene & 0.63 & 0.61 & 0.26 & 0.09 \\
Total of 16 PAH & 21.06 & 15.66 & 3.81 & 15.84 \\
Other PAHs & & & & \\
(calculated without response factors) & 11.60 & 5.25 & 1.24 & 9.73 \\
TOTAL PAH & 32.66 & 20.91 & 5.05 & 25.57 \\
\hline
\end{tabular}

486

487 The analysis was performed in duplicate. ND = not detected 
489 Table SI1: Effective concentration (\%) for biochars at 10, 30 and 50\% root length reduction, i.e., $490 \mathrm{Ec}_{10}, \mathrm{Ec}_{30}, \mathrm{Ec}_{50}$ in three plant species.

491 n.p. = non phytotoxic

492

\begin{tabular}{lllll} 
Biochar & Plant species & $\mathbf{E c}_{\mathbf{1 0}}$ & $\mathbf{E c}_{\mathbf{3 0}}$ & $\mathbf{E c}_{\mathbf{5 0}}$ \\
\hline \multirow{4}{*}{ CO } & C. sativus & 0.06 & 0.12 & 0.30 \\
& L. sativum & n.p. & n.p. & n.p. \\
& S. saccharatum & 0.07 & 0.14 & 0.36 \\
& & & & \\
\multirow{4}{*}{ PO } & C. sativus & 0.07 & 0.15 & 0.37 \\
& L. sativum & n.p. & n.p. & n.p. \\
& S. saccharatum & 0.09 & 0.18 & 0.44 \\
& C. sativus & & & \\
GM & L. sativum & 0.3 & 1.4 & 3.3 \\
& S. saccharatum & 2.4 & 3.1 & 3.7 \\
& & 0.1 & 0.6 & 1.6 \\
& C. sativus & & & \\
\multirow{2}{*}{ WS } & L. sativum & 0.9 & 3.3 & 7.1 \\
& S. saccharatum & 3.6 & 5.0 & 6.2 \\
& & 0.2 & 2.8 & 14.7
\end{tabular}

493

494 
495 Table SI 2: Effects of biochar type on root elongation (main effect, i.e., mean of various 496 amendment rates) of plant species at end experiment in comparison with the commercial 497 amendment CA (Tuckey's HSD test; $\mathrm{P} \leq 0.05$ ). Letters: statistical significant differences among 498 chars within same species.

499

Species

C. sativus

S. saccharatum

L. sativum
Biochar/Amendment

CA

$\mathrm{CO}$

$\mathrm{GM}$

PO

WS

CA

$\mathrm{CO}$

GM

PO

WS

CA

$\mathrm{CO}$

$\mathrm{GM}$

PO

WS
Root length (mm)

46.4 a

$19.1 \mathrm{c}$

$33.7 \mathrm{~b}$

$33.9 \mathrm{~b}$

49.7 a

$19.2 \mathrm{a}$

$12.5 \mathrm{~b}$

$11.0 \mathrm{~b}$

$13.5 \mathrm{~b}$

$17.8 \mathrm{a}$

56.1 a

56.8 a

$24.9 \mathrm{c}$

64.9 a

$40.9 \mathrm{~b}$ 